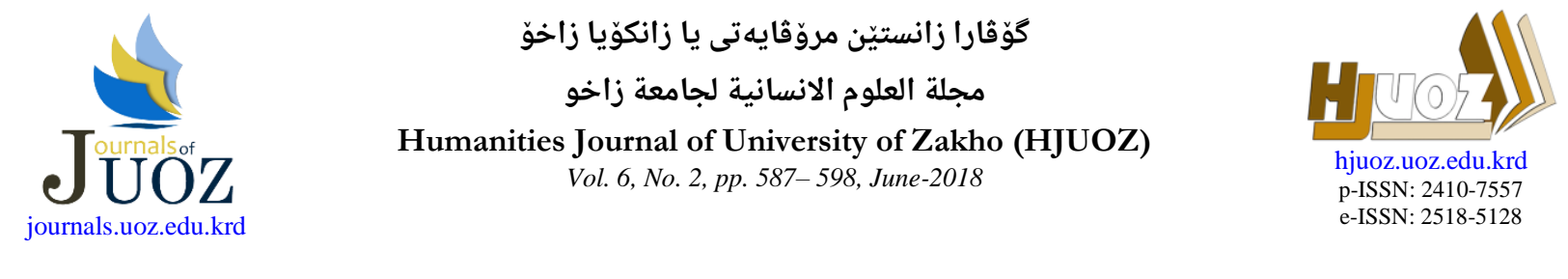

\title{
Traditional Methods of Dealing with Conflicts among IDPs in Duhok Governorate in Iraqi Kurdistan; including a case study of Yesidi mediators
}

\author{
Maamoon A. Mohammed ${ }^{1}$, Zeravan Sulaiman Sadeeq², Jehan A. Abdullah ${ }^{3}$, Sanaz Kamali ${ }^{4}$ \\ 1College of Humanities, Department of Peace and Human rights, University of Dohuk, Iraqi Kurdistan. \\ 2College of law and political science, University of Dohuk. Iraqi Kurdistan. \\ 3College of Humanities, Department of Peace and Human Rights, University of Dohuk. Iraqi Kurdistan.
}

4Civil Peace Forum (forumZFD)

\begin{abstract}
Received: 12/2017 Accepted: 06/2017 Published: 06/2018 https://doi.org/10.26436/2018.6.2.478
\end{abstract}
\begin{abstract}
:
The last influx of internally displaced people (IDPs) into Kurdistan Region-Iraq, with little hope of returning home, has made peaceful coexistence within and between religious groups both in host communities and IDP camps. However, which are based in Islamic and sometimes contradict minority religions' customs and beliefs. This serves to undermine their traditions' ability to confer the dignity and positive identity essential to a peaceful, stable society, and even to erode those traditions themselves to the point of extinction.

Nevertheless, the practice of traditional methods of conflict resolution has shaped social interactions divisions and enabling the mending of broken relations within and among groups. A collaborative project implemented in 2016 to promote social cohesion and identify conflict resolution methods used by religious groups in six camps near Duhok, this paper focuses specifically on those of the Yezidis. This religious group comprises about $85 \%$ of IDPs in the area and tends to experience most resentment in their adopted neighbourhoods; however, their use of traditional methods was found to be higher than other groups. Yezidi mediators include middle level and grassroots actors, making them well placed to be effective in peacebuilding because of their extensive interaction with disputing parties and their capacity to constantly adapt traditional methods to situations.

After discussing the methods used generally by displaced religious minorities, the paper presents the characteristics of Yezidi mediators and concludes that these methods are essential to developing sustainable peace because Yezidis in Kurdistan are proud to conform to them, hence, understanding and reduce resentment.
\end{abstract}

KEYWORDS: Mediator, Traditional methods, IDPs, Conflict, Conflict resolution.

\section{Introduction}

Although many areas have been liberated from ISIS, they remain in need of reconstruction before services are adequate for internally displaced people (IDPs) to return home. Meanwhile, the Iraqi government and the Kurdistan Regional Government (KRG) are in dispute over some of these areas causing further delays. Coupled with lack of confidence in the general situation, this makes it likely that most IDPs will remain in Duhok Governorate for the foreseeable future (UoD social cohesion round table 2017). Despite this, little research has focused on their traditional resolution methods; in particular, there is scant information about those of the Yesidis, despite the fact that they constitute a large majority of the IDP population.

Consequently, this paper is based on research investigating the methods used and the actors involved in resolving, preventing or mitigating conflict, both inside IDP camps and in the host community. The research was funded by the Deutsche Gesellschaft für Internationale Zusammenarbeit (GIZ) project for Social Cohesion and jointly implemented from October to December 2016 by Forum Civil Peace Service (ForumZFD) and the Centre for Peace and Conflict Resolution Studies (CPCRS) of the University of Duhok (UoD).

There is a long history of displacement of ethnic and religious minorities in northern Iraq, predominantly from the Iraqi disputed areas. Duhok Governate, itself, comprises three main religious groups: Muslims, Yezidis and Christians, while the inhabitants of IDP camps are mainly Yezidis, Christians, Muslims (including different sects), and Turkmen. The research focused specifically on the recent influx of 2014 and thereafter. Although the 
number of IDPs varies according to information source, figures from the International Organization for Migration (IOM) point to the displacement of 836,670 IDPs following the Mosul crisis (IOM 2014), with 500,000 in the governorate of Dohuk. Of 27 camps, 18 are in Duhok, 4 in Erbil and 5 camps in Sulaimaniyah. Several camps Bersivy 1, Chamishko, Dawidiya, Qadya, Bersivy 2 and Kabartu 1, Mamilyan and Kabartu 2 - contain groups of families that differ ethnically and religiously. Yezidis constitute $85 \%$ (26,706), Sunni Kurds 9.7\% $(3,075)$, Shia Kurds $4.1 \%$ (1,299), Sunni Turkmen $0.5 \%$ (176), Christians $0.3 \%$, Shia Turkmen 0.2\% (93), Sunni Arab 0.2\% (55), and there is one Shia Arab. (No data is given for Sunni Turkmen) (BRHA Duhok 2016).

The purpose of the research project that this paper is based on was to assess the role traditional resolution methods used by IDPs of a variety of different ethnicities play in enhancing social cohesion by identifying the methods and actors involved in conflict resolution/prevention. With the more specific aim of identifying Yesidi methods in particular, this paper, firstly, presents an overview of the main categories of methods used by all ethnicities and indicates where the main religious minorities refer their cases to. This provides an understanding of the context for the case study of the methods and mediators of the Yezidi people which follows. While appreciating the importance of official methods, the paper concludes that traditional methods of resolving conflict can provide a road map for people to live together peacefully as communities in Iraqi Kurdistan as they consider themselves socially obliged - and proud - to use these methods.

\section{Literature}

There is virtually no literature on Yezidi resolution practices, making this study especially needed to fill this gap in scholarship. Research conducted by Strang and O'Brien (2017), which primarily investigated genderbased violence among displaced persons, identified the social connections and levels of trust among displaced people. This found that Yezidi IDPs "go to the family first for help to resolve any conflicts, then the tribal leader or the Mukhtar [sector leaders], and then Baba Sheikh [the Yezidi spiritual leader]. They would only involve the police or the courts if the problem could not be resolved by these means" (p. 43). Moreover, the study emphasised the important role religious leaders in Yezidi communities play in resolving conflicts and that Yezidi people will obey instructions issued by them. These findings are confirmed in the current study, as indicated in the results below.

\section{Methodology}

Since there is little previous research on this subject, the approach used here is primarily deductive as it seeks to discover information about traditional conflict resolution methods rather than to prove a preconceived hypothesis. Moreover, in line with Eisner's assertion (1991:58) that qualitative research study can help us "understand the situation that is otherwise enigmatic or confusing", the approach used is basically qualitative although, due to the large number of interviews involved, it also provides useful statistical data. The study is based on 75 structured interviews that focused on answering the following questions: When do conflicts occurs? Who is called to mediate them? Who will be accepted by communities to mediate conflicts and according to which criteria? Does the type of conflict affect whether conflicting parties prefer traditional methods over court proceedings? What are the background and experiences of persons, institutions, and informal bodies inside and outside camps? Do persons or institutions mediating conflicts feel adequately prepared to do so? The interview participants were community leaders and other actors involved in resolving conflicts and conflict prevention in six IDP camps (Kabartu 1, Kabartu 2, Qadia, Bajid Kandala 2, Chammishku, and Sharia) across three municipalities (Duhok, Zakho and Sharia) in Duhok Governorate..

To remedy the pitfalls of qualitative research, such as personal bias, different methods and steps were taken to ensure the validity and reliability of information. Firstly, prior to the field research, literature reviews of previous studies, government policies, and documents as well as knowledge about the cultural taboos 
- were conducted. As the research was conducted in cooperation with GIZ, which had been providing services in the camps, this helped with the credibility of the project in the eyes of the informants. Previous researchers and research conducted on different subjects in these camps also made the research team's work more acceptable to the inhabitants, and we attended workshops and meetings with experts in the areas to improve our background knowledge before conducting the field observations.

The familiarity and experiences that the researchers had in these camps in conducting many workshops, and contacts they had made, provided the appropriate informants and helped to increase the open safe spaces for informants to feel comfortable to talk. The research teams discussed the plans and findings at the beginning and end of each day, respectively, to ensure the project ran smoothly and appropriately.

Starting with the contacts that the researchers already had, snowball sampling was used to find actors involved in resolving conflicts. These included Mokhtars (community leaders) and other religious leaders. None of the interviews were tape recorded so as to let the informants talk more freely and a reflection question was formulated and given to each team member to be filled in after each interview. Existing conflicts were recorded using Excel, detailing the following: sources of information; the name of researcher making notes; details of the conflict; and other comments. Interviews with stakeholders involved in dealing with conflicts and social cohesion in camps and host communities were recorded in the same way. Three researchers cooperated in writing and mapping out the Excel sheets so that all the researchers could access them and comment. All data was stored in shared on-line documents using coding names, and folders for interviews in the camps and cities were separated under different names to preserve anonymity.

The interview material was then analysed according to the categories identified above. This provided the data concerning mediators' responses regarding the following subjects: their role and involvement; their impact, influence, interests, needs; possible future contributions, concerns/fears; connection to others; and quality of relationships. This, firstly, provided an overview of conflicts experienced by IDPs and resolution methods used, and more detailed study of the interview material was then used for the case study of specifically Yezidi methods.

\section{Results}

\subsection{Characteristics of Conflicts involving IDPs:}

Although many interviewees reported tolerable relations among their communities, the research indicated tensions and latent conflicts between and within the different IDP communities in Duhok Governorate. They existed between and within different tribes; between and within different family circles; between IDPs and the host communities; and between different IDP religious groups, such as Yesidiz and Muslims. Conflicts also existed between IDPs and NGOs regarding lack of sensitivity in project implementation. Some of these tensions are on-going, some are recent and others are old. Based on the research team's assessment, the different types of conflicts affecting communities that are resolved through traditional means were identified: vendetta, fights, land conflicts, children related conflicts, finance, debt conflicts, car accidents, women-related conflicts (honour and marriage related) and conflict arising from killing. There are also different types of hidden conflicts, including conflict based on historic issues and religious hatred, identity and cultural differences conflict, jobs/markets conflicts, rural versus urban conflicts, stereotypes and discrimination conflicts.

\subsection{Resolution Methods:}

The research team also identified the main traditional methods used as avoidance, amicable resolution, and mediation as explained below.

\section{Avoidance}

Avoidance is used to prevent damage to relationships when conflicting parties are from the same family circle or tribe. Affected parties ignore the conflict and avoid talking about it as this may affect the reputation of the conflicting 
parties. This also occurs when one party has greater power and the other party can do nothing about it.

\section{Amicable resolution}

Amicable resolution is used mostly when conflicts occur between and among the family members and within tribes. A person from the same family or tribe intervenes to resolve the conflict. Causes of such conflicts can be family-based, including marriage and inheritance, or social conflicts. They may be minor or they may seriously affect the reputation and the honour of the family or tribe. Hence, it is better to be resolved within the family, as they do not want outsiders interfering in their affairs.

\section{Mediation}

The majority of community conflicts are resolved through mediation by a family member, relative, tribe member or leader. Mediation can be used for small and difficult cases, such as vendetta, as well as death or injury by car accident. The latter are considered easier than purposeful killing and most likely such conflicts are resolved by giving an amount of money to the damaged party. The mediator can intervene both when conflicts occur and after they end to ensure good relations, intervening to resolve the conflict and also to transform the conflict by reconciling and strengthening the conflicting parties' relationship. Many times, when the official court ends a case, this does not guarantee the end of the conflict, while traditional methods most likely will both end the conflict and rebuild the relations between conflicting parties.

There are also Kurdistan Democratic Party (KDP) social committees/institutions to deal with cases of conflict between communities. These committees are run by leaders who are respected by all communities living in Kurdistan. The committees provide free services to the communities and their decisions do not oblige conflicting parties to accept. Nevertheless, almost all cases are resolved by them. As above, when a conflict ends, the committee follow its resolution by trying to strengthen the relations between conflicting parties. They follow the conflict case for a period of time until they are sure that it is ended and relations are back to the normal - and in most cases to a better situation. This approach is summed up by an Arabic proverb that says 'After the animosities, better relations'. Whether an individual or a community committee, mediators may pay visits to conflicting parties or organize feasts and invite them with the presence of their families and other community's leaders.

\subsection{Conflict Referral:}

The official Islamic court, Assayish (official security organisation)Violence against Women (VAW) offices and the police are the official organisations that receive most cases of conflicts, almost all deal with cases that have not been resolved by other methods. They are the most powerful and influential mediators apart from the KDP social committees, which only intervene in difficult cases. Only when the case goes to one of these five organisations is the resolution legally enforced on the conflicting parties. However, the most available, accessible and confidential mediators are the elders and, in the areas researched, the host communities and the Yesidi communities have the most mediators to refer their cases to.

As detailed in the next section, Yezidis prefer to refer their cases to their own spiritual leaders and tend to avoid using the official Islamic courts. Although Christians' circumstances are not very different from the Yezidis, they refer most of their cases to the court as, according to the informants, it is more modern and more just. There are times where the resolution of conflict contradicts the religion of Islam; for example, cases concerning divorce. The court refers those cases to the Church. Similarly to the Yezidis, most Christians normally live in villages together with other Christians and separate from Muslims but, when Christians do live with Muslims, they have no problem with social cohesion.

Muslims refer almost all their social conflicts cases to Muslim clerics. Among others, one reason given was that they wanted confidentiality since, once the case goes to the official court, it will be disseminated to many people, which may bring disgrace, shame, and stigma to the family. Other conflicts, such as vendetta and blood feuds (in both Kurdish and Arab communities) are referred to Aghas (tribal leaders). Aghas may intervene and 
resolve cases before they go to court, or they may intervene after the courts' decision as a means to reconcile the conflicting parties.

Arab interviewees indicated that they only refer their cases to the court, which contrasts with Arab tradition in other places in Iraq. This statement might have been an indication that they would like to act (or to be seen to act) according to the law, so that they do not get into trouble in Kurdistan.

Despite these overall trends, there are people from all communities that refer their conflict cases to the court. Neither the tribal leaders nor the community leaders wanted people to refer their cases to the official courts. They consider them more modern and to give results that create win-lose situations, so they do not serve to foster the harmony in the situation. Other miniority IDP communities that reside in Dohuk - such as Shabak, Turkemen, Shiia use more the formal/official system rather than traditional methods of resolving conflicts as they are few in number compared to Yesidiz, Christians and Muslims, and so have fewer mediators to refer their cases to.

In the host community, Aghas (tribal leaders) are the most accepted mediators among all communities. Whenever conflicts occur among and between communities, they are considered the best actors to intervene. They are the most accepted persons among non-Muslim communities, in part, because almost all of them are secular. According to Agha informants, they sometimes ask the court to postpone cases to allow the Agha time to intervene and resolve the conflict case. According to interviewees, Nihad Barzani who is especially involved in dealing with complicated conflict cases. He is the only mediator that deals with prevention - the prevention of violence and destructive conflicts within all communities.

The two figures below show the various bodies that the interviews indicated that IDPs may refer to for them to resolve their conflicts: 1) within the host community and 2) within IDP camps.

In the first diagram, an arrow goes from the court to the Aghas indicating that sometimes the court ask Aghas to intervene. Similarly, an arrow goes from the court to the Yesidiz Spiritual Council and to the Christian Church because, recently, when the court finds that the resolution of conflict contradicts the Yesidi or Christian religion, it refers the cases to these.

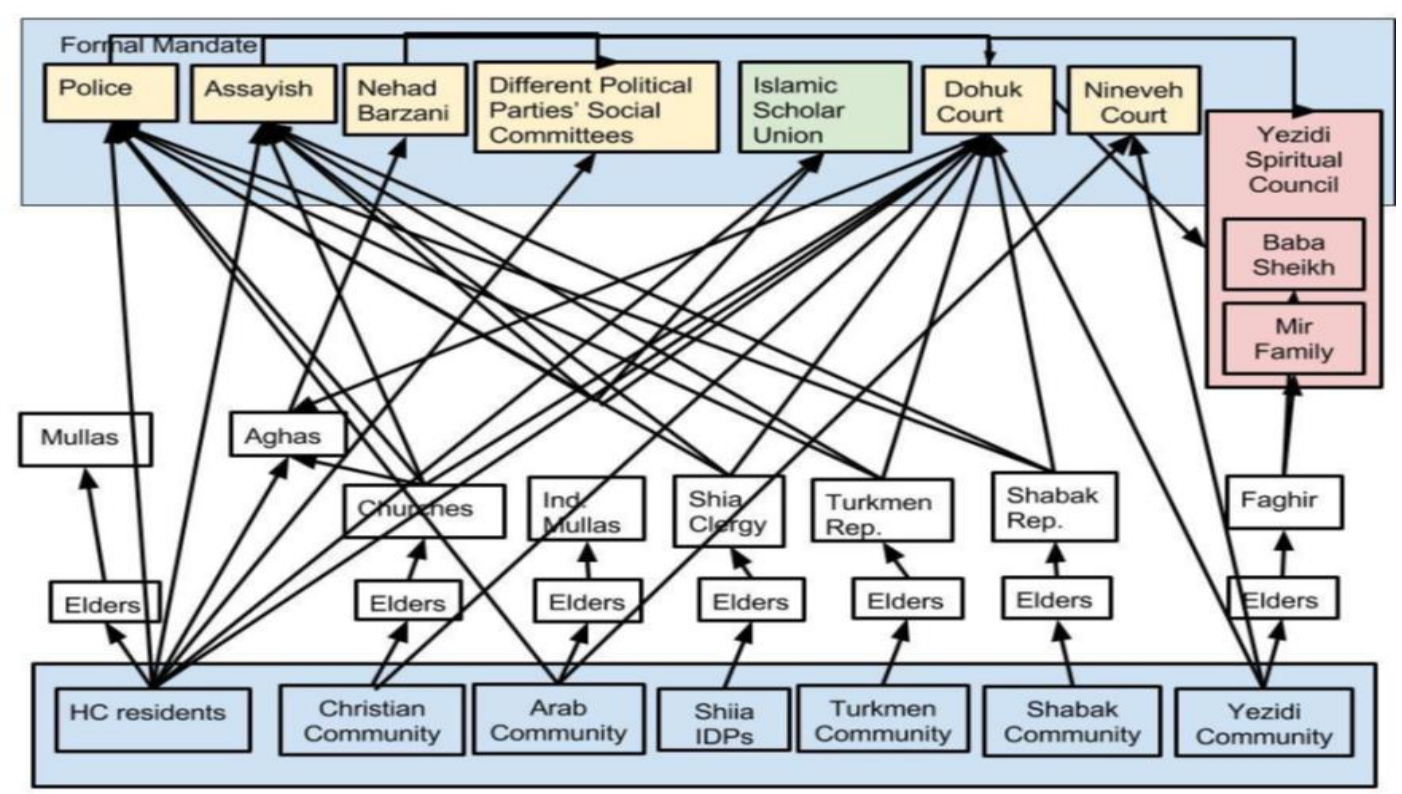

(Yellow boxes indicate governmental institutions; red boxes indicate Yezidi mediators; green indicates Muslim mediator. The size of the boxes is not significant.)

Figure 1. Conflict Referral: IDPs in the Host Community 


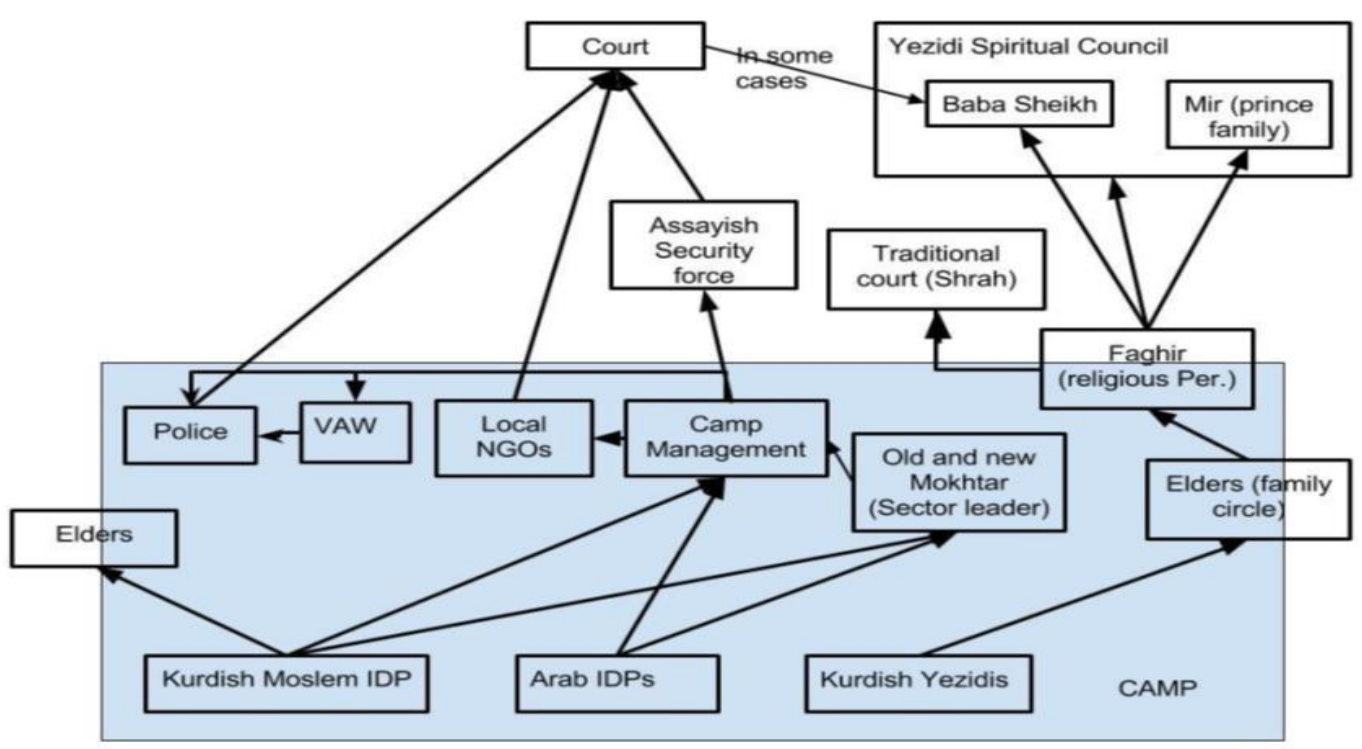

Figure 2. Conflicts Referral Cases (IDPs inside the Camp) (The size of the boxes are not significant)

As indicated in the diagram above, within the camps, there are elders, camp committees and Moktars. The elders are the most accessible while the camp committees are more authoritative. The Moktars have the least power inside camps. They refer almost all cases to the camp management. Conflicting parties can also refer to the police, VAW and NGOs, before taking their cases further as indicated in Figure 2. As with the Figure 1 for the host communities, an arrow indicates that the courts may refer cases to the Yesid Spiritual Council. The diagrams show that the host communities have more mediators than the IDP communities while, in the camps, the Yesidiz have more mediators. This correlates with the number of people that each community has. For example, there are few Muslim communities inside the camps; hence, they have few mediators inside the camp. Therefore, most Muslim IDPs refer their cases to the camp management as they have more power and influence.

\subsection{Case study: Accepted Yezidi Mediators:}

The interviewed Yezidis indicated that Yezidis prefer their cases to be dealt with within their family circles; so they refer their cases to elders, and if they are unable to resolve a case, they refer them first to their religious leader (Faghir), as this is considered to be fair. They feel this is their duty as a Faghir is more pious and closer to God. If the case is not resolved by the Faghir, they refer it to a Pir (this is a spiritual leader who regulates the religious affairs of their followers and has a higher religious rank than a Faghir). If it is not resolved there, they send it to the Shra Court or the Yezidi Spiritual Council, that is, the Baba Sheikh or their Mir (prince) (or his son). All these people are well respected among the Yezidi community.

According to the Yezidi interviewees, a good mediator is considered to be one who is able to relate sacred religious texts to the conflict to be resolved. While these various religious leaders do not hold any political positions, they are respected and have significant influence on Yezidi society. Moreover, if conflict occurs between Muslims and Yezidis, the Yezidi leaders generally have good connections with Muslim tribal leaders but not with Muslim religious leaders, and they resolve the conflict together. They very rarely refer their cases to the court as the court laws are based on the Islamic Sharia.

\section{Mir Family (Yezidi Prince)}

The Mîr or Yezidi Prince is the head of the Yezidis, a hereditary role. He is recognized as the official representative of their holy Tawsi Melek on Earth and represents his people at all national and international conferences. The current Mir is Mir Tahseen; however, as he was away at the time of the fieldwork, the researchers interviewed his son, a young law graduate, who intervenes in many different kinds of conflicts cases for the Yezidis on behalf of his father. These have included 
kidnapping girls, killings, tribal conflicts, etc. Such conflicts are firstly dealt with by Tahseen's son and his consultants (usually other members of the family such as uncles), or they involve the Baba Sheikh. Conflicts cases are rarely sent to court. The cases are usually brought to Tahseen's son or he is asked to intervene by the conflicting parties. He listens to each party separately, then, he gathers them together in the presence of other Sheikhs (members of the Yesidi Spiritual Council). Mir family members also intervene in conflict cases with Muslims, Kurds and Arabs and have good coordination with the nearby Kurdish Muslim and Arab tribes. The Mir family also has good communications with KRG institutions, but not with Muslim religious leaders.

The young Mir feels he is adequately prepared to do conflict resolution; as a leader, he is well known to the host community and the government. People listen to him and respect him. He has experience, knowledge and authority in resolving conflicts.

\section{The Baba Sheikh (Yezidi Spiritual Leader)}

The Baba Sheikh is the spiritual head of the Yezidis and is appointed by the Mir. He derives from the Yezidi Sheikh caste and currently resides in the town of Shekhan. He attends all important Yezidi religious meetings and ceremonies, especially those conducted at Lalish. Once a year, the Baba Sheikh visits Yezidi villages to give his blessings and conduct ceremonies. During these visits he also resolves disputes among the villagers.

All the most complicated conflicts cases that could not be resolved by other people or by the official court are taken to the Baba Sheikh. He is also involved in conflict cases between Yezidi tribes and between other communities and Yezidis, and especially conflicts that occur between Muslims and Yezidis. For example, the Baba Sheikh intervened in and resolved a conflict between a group of Yezidis and the Muslims of Harki tribe in the Akre Mamylian camp. Many times the Baba Sheikh, with other political actors, intervenes to resolve conflicts. The Baba Sheikh has good relationships with many other communities' tribal leaders. He also works on conflict prevention, giving orders, speeches and advice to his communities to promote peace and social cohesion.
People listen to him and it is considered a sign of respect for people to accept his offer to resolve conflict. He was confident that he could easily resolve complicated cases of conflicts, even cases concerning conflicts with other communities, including Muslim communities. There are similarities between the Baba Sheikh and the Islamic Mullahs as both are respected religious people. However, in contrast to Mullahs, who study religion and tradition, the Baba Sheikh's position is inherited, and he has years of experience in reconciliation and conflict resolution. Yezidis and non-Yezidis respect him and Yezidis admire him. Both the Baba Sheikh and his son are interested in dialogue between Yezidis communities and non-Yezidis.

The Baba Sheikh has very good relationships with other communities' leaders and eminent government people and good communication with KRG institutions and other tribal leaders, but not with Muslim religious leaders, and also with other people representing the Yezidis such as Mir Tahseen. The Baba Sheikh regularly meets with other Yezids communities and religious clerics, such as Mirs, Pirs, and Faghirs.

Small cases of conflicts are not dealt by the Baba Sheikh but by Shra Courts or respected elders, such as Faghirs.

\section{The Shra Court (Yezidi Court)}

The Shra Court is a traditional court consisting of tribal leaders, community leaders, and religious leaders. They gather in the house of a tribal leader to discuss the referred conflict cases. The court brings the conflicting parties together and tries to resolve their conflicts and most of the time both parties accept the resolution it provides. Sometimes the court gives an order, such as to pay a fine and/or compensation to the damaged party. Usually, both conflicting parties agree on the resolution; however, if one party does not accept the resolution the court may decide to punish that party. In some cases, the court has even decided to expel people from the area. The party who did not accept the ruling can then only return if they accept the court's resolution. Most of the time, both parties are reconciled and forgive each other before they leave the court.

The Shra Court applies traditional customs and laws when resolving conflicts. Different types 
of conflicts are referred to the Court including family conflicts, killing, blood feuds, and kidnapping of girls. When a conflict cannot be resolved by elders, they refer it to Shra Court.

Shra Courts exist in every camp and city where Yezidis exist. However, the Duhok courts do not consider their decisions legitimate, but they know about it and, sometimes, they refer cases to them. Yezidi people prefer Shra Court, considering it more legitimate as it is based on their traditional laws. It is free, more accepted by people, and part of the resolution is that the conflicting parties forgive one another in the Court. If it cannot resolve the conflict, it refers it to the Baba Sheikh.

\section{Faghir (Yezidi religious person)}

Faghirs are religious persons in the Yezidi community with an informal mandate to intervene in conflicts. People respect them and accept their judgement. They also intervene in conflicts between Yezidis and Arabs, including those relating to the kidnapping of Yezidi girls by Muslims in the camps. In an interview in one camp, a Faghir said that they have good relations and cooperation with the Baba Sheikh and the Yezidi Spiritual Council. Once people address their issue to a Faghir, he listens to the both parties in the conflict, then, he resolves between them and people accept whatever the Faghir offers. However, in the interview, the Faghir admitted that during his life he had failed in some cases, they were closed-minded people. When people refuse the Faghir's offer it brings disgrace and shame.

Social and family conflicts between Yezidis IDPs and Yezidis host community are also usually dealt by Faghirs. If a conflict cannot be dealt by Faghir, he refers it to the Baba Sheik. Faghir phones, meets and cooperates with the Baba Sheikh and seeks his advice in resolving and preventing conflict among Yezidi communities and between Yezidi and nonYezidi communities.

Many local NGOs argued that Faghirs are biased, and always support men's side in conflicts involving women. Most followers accept whatever Faghirs says because of their religious position. They believe the Faghir is fair and neutral in resolving conflicts. Most of the interviewed Faghirs had little formal education.

\section{Elders (White Beard or Reh Spee)}

Each family circle has a White Beard (elder) person who intervenes in family circle conflicts. In Yezidi communities, White Beard people also intervene in conflicts in the wider society. Although in the Muslim host communities almost every elder person is a White Beard person even if he does not have a white beard, in the Yezidis communities, only the White Beards have beards. These people are religious elders who are generally respected. They live in the tents among IDPs as well as in the cities with the host community.

The White Beards' method of resolving conflict is very simple: they listen to conflicting parties. People consider their solutions to be fair and it's considered shameful if people refuse them. Most of the Yezidis White Beards felt they were adequately prepared to do mediation. However, Yezidi White Beard's only intervene in simple uncomplicated conflicts; otherwise people refer bigger cases of conflicts to the Baba Sheikh or to the Shra court.

The Yezidis are a conservative society and they do not like other people to know about their conflicts. Therefore, Yezidi people prefer to go to White Beards as they are part of their own people, so it is considered more confidential. They also sometimes work to prevent conflicts by giving advice to the communities. The camp management usually asks them to spread messages of peace when conflict occurs between tribes or communities.

\section{Discussion: Mechanisms of Resolving Conflicts among IDPs}

The main communities living in Duhok are Muslims, Yezidis, Arabs and Christians. These communities have been living together a long time and there are many similarities regarding mechanisms for resolving conflicts. One important similarity is that religion plays an important role in all these communities. Many members of these communities search for solutions for their conflicts within their own religion and address their issues with their religious leader. A further similarity lies in the kinds of tribal heritage system and their legitimacy to address conflicts, which were identified within the Kurdish, Yezidi and Arab communities. The three communities use old stories and elders' sayings to resolve conflicts. 
On the other hand, differences not only go back to the obvious religious and ethnic differences but also to the respective social roles as a member of majority or minority community, as well as many context-related (economic, social, political) factors. Since the laws in Iraq are mostly based on Islam (Sharia), this has forced the Yezidis to resolve most of their conflicts through religious leaders as there are many laws in Iraq that contradict the Yezidi religion. Recently, this has led the KRG to issue an order to the judges of the official court to refer the resolutions of all conflicts that contradict the Yezidi religion to the Yezidis' Spiritual Council.

The different religious communities in Kurdistan have been living together throughout history. Kurds live with Arabs; and they have adapted part of Arab culture and traditions. Most cultures consistently borrow and adapt practices from cultures that they have contact with (Van Cott 2000, 218; see also Boege 2004: 15 and Mac Ginty 2011:1). While interviewees overwhelmingly wanted to preserve their traditions, their traditional methods are not static, but are in constant change over time to adapt to the contemporary situation: they are flexible. In particular, the Yezidis' changing circumstances have made them adapt and preserve similar traditions to a great extent, especially when the law and customs of the society where they live is based on a different culture - and this culture has been dominant throughout history. Thus, when power is centralized in a different culture, ethnic and religious minorities try to preserve their traditional methods by adapting them. This is the case with the Kurds as, in general, they fear their traditions becoming extinct. Thus, as Hobsbawm (1983, 1) explains: "[t]raditions which appear or claim to be old are often quite recent in origin and sometimes invented".

In traditional methods, as the interviewed mediators asserted, people choose them because everyone becomes part of the process and takes responsibility for resolving the conflict. Moreover, they are not coercive; people come to them voluntarily with the intention of finding a solution but if they do not like it they do not have to accept it. However, people are not simply individuals, they are also part of the community, so they may feel pressured to participate in the mediation and resolve the conflicts. When a disputant refuses the resolution provided by traditional methods, he/she is considered a consensus breaker, antisocial, and they may be ostracised for not conforming to the society's roles and norms. But, when they accept the resolutions, their community considers them the ideal citizen, a consensus builder.

Thus, it is the responsibility and in the interests of all that the process succeeds. In Kurdistan, usually all the family circles or the tribe contribute to repairing the damage, emphasising collective responsibility and duties in resolving conflict. People have the belief that mediators solve the issue through their experience and respected position in the community. The mediators also have a lot of social credence invested in the outcome and will do everything possible to resolve the conflict and, according to interviewed mediators, many times the mediator pays from his pocket to contribute to resolving conflicts. These mutual contributions and responsibilities result in an increase in the psycho-social and spiritual dimensions of conflict transformation. From Lederach's (1997) perspective on peacebuilding, whereby grassroots actors are usually effective in peacebuilding because of their excellent interactions with disputing parties and inside knowledge of the conflict contexts, the traditional methods practiced by IDPs are well placed to provide sustainable and transformative resolutions. Lederach describes the various roles involved in peacebuilding as a pyramid divided into three levels: the highest level comprising the top official leaders who are powerful but quite distant from the local issues involved; the middle level includes ethnic and religious leaders, who interact with both the top level, and the grassroots level with the grassroots leaders comprising the bottom of the pyramid. Traditional mediation in Kurdistan involves both the middle levelrepresented by local leaders (such as the Baba Sheikh, Mir Tahseen, and tribal leaders) who are able to influence and listen to the grassroots leaders and to encourage bottom up interaction - and the grassroots actors and members of local communities (such as elders and Faghirs), who work at the bottom level of the pyramid. The latter not only experience the day-to-day 
impact of conflict but are also best positioned to resolve conflicts because they are aware of their context, the needs and the concerns of the community. Hence, the grassroots actors in peacebuilding play an important role in resolving conflicts at the local level (see Lederach 1997), especially when they liaise with the middle level.

\section{Conclusions}

The paper concludes that traditional methods of resolving conflicts are effective among IDPs and host communities. Overwhelmingly, interviewees wanted to preserve their tradional methods and were happy about their continuing existence while the mediators felt competent and confident in their work. The use of traditional methods was higher among Yesidi IDPs than IDPs from other minority groups. As the interviewed mediators argued, the traditional methods of resolving conflict are reconciliatory, retributive, consensus building, and free of cost. Moreover, the study supports the idea of using tradional resolution methods in line with the other modern methods. As Lederach (1997) emphasises, peacebuilding should have space for diverse actors, from the state to civil society and through to local community members who are faced with the impact of conflict on a daily basis.

The longevity of the practice of traditional methods has shaped the communicative practices of different groups of people and so influences social interactions which result in mending broken relations within and among groups. The middle level liasion with the grassroots level (for example, liason between the Baba Sheikh and Faghirs), as well as with different tribal and spiritual leaders, bridges social divisions and helps to restore the social fabric of the society by establishing useful bonds. As the middle level shapes the process, negotiates the outcomes and determines the response, it is mediators at this level tend to lead the way to reconciliation. Meanwhile, since their mediations are both rooted in and involve the community around them, it is in the interests of all that the results tend to be transformative, increasing social cohesion while resolving conflicts.

Despite their effectiveness, there are drawbacks to traditional resolution methods which need to be ameliorated. In particular, the lack of women's involvement in decisionmaking processes is not in line with the increasing role women play in society, similarly, younger people have no role in these processes. A further drawback is that, despite the effective role that traditional mediators play in resolving conflicts, they do not have legal authority and this hinders their work.

\section{References}

Strang, A. and O'Brien, O. (2017). Who can I Turn to? Institute for Global Heath and Development, Queen Margaret University, Edinburgh. Available at https://jliflc.com/wp/wpcontent/uploads/2017/07/2017-QMUTearfund-Who-Can-I-Turn-To-En.pdf (Accessed 09/06/18).

Boege, V. (2006). Traditional approaches to conflict transformation: Potential and limits. Breghof Research Centre for Constructive Conflict Management. Available at http://www.berghof-handbook.nd (Accessed 03/10/17).

Boege, V. (2011). Potentials and Limits of Traditional Approaches in Peacebuilding. In B. Austin, M. Fischer and H. J. Giessmann (Eds.). Advancing Conflict Transformation: The Berghof Handbook II (pp. 445-449). Barbara Budrich Publishers: Opladen/Farmington Hills, BRHA Duhok. (2016). Profile and General Information IDPs and Refugees in Duhok Governorate. Available at http://www.brhaduhok.org/brha_du/stories/idps-and-refugeesin-duhok-governorate (Accessed 11/11/2017).

Deutsch, M. (1973). The Resolution of Conflict. New Haven: Yale University Press. Eisner E. W. (1991) The Enlightened Eye: Qualitative Inquiry and the Enhancement of Educational Practice. Minnesota, US: Merrill Corporation.

Hassin, A. (2013). Tribes and conflict management in Iraq, Proceedings of Communication and Conflict 3rd Global Conference. Oxford, UK: Interdisciplinary.net, 1-13.

Hobsbawm, E. (1983). Inventing Traditions. In E. Hobsbawm and T. Ranger (Eds.). The Invention of Tradition. (pp. 1-15) Cambridge: University Press. 
IOM (2014). IRAQ Crisis Response. Available at http://reliefweb.int/report/iraq/iraq-crisisresponse-displacement-map-23-august-2014 (Accessed 12/6/2017).

Lederach, J.P. (1997). Building peace: Sustainable reconciliation in divided societies. Washington DC: United States Institute for Peace.
Mac Ginty, R. (2008). Indigenous PeaceMaking versus the Liberal Peace, Cooperation and Conflict, Vol. 43, 2, 139-163.

Van Cott, D.L. (2000). A Political Analysis of Legal Pluralism in Bolivia and Colombia, Journal of Latin American Studies, 32, 207 234. 


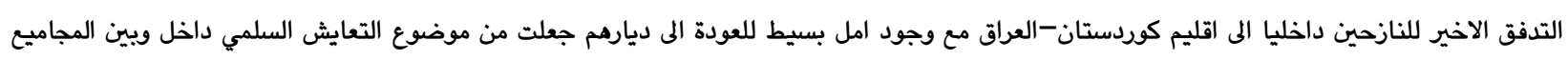

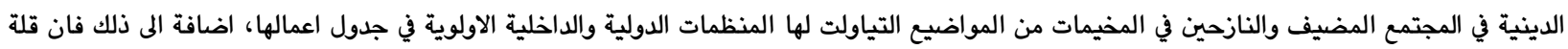

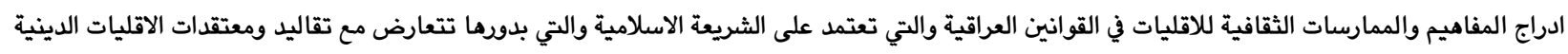
والذي من شأنه ان يقوض من قابلية ومكانة التقاليد الخاصة بالاقليات و الحفاظ على هويتهم وذلك لان الحفاظ عليها تعتبر ضرورية جدا لقيام مجتمع يعم فيه

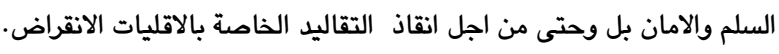
ان ممارسة الطرق التقليدية في حل النزاعات شكلت تفاعلا اجتماعيا و ارست جسورا بين التقاطعات الموجودة بين المكونات المختلفة في المجتمع بالاضافة الى بلى

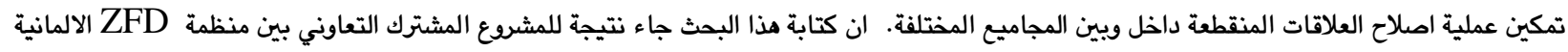
وجامعة دهوك ويدعم مالي من منظمة GIZ الالمانية والذي نفذ في دهوك عام 2016. مذا المشروع الذي تناول موضوع تعزيز التماسك الاجتماعي وبيان طرق حل النزاعات المستخدمة من قبل المجاميع الدينية في ستة من مخيمات النازحين في دهوك.

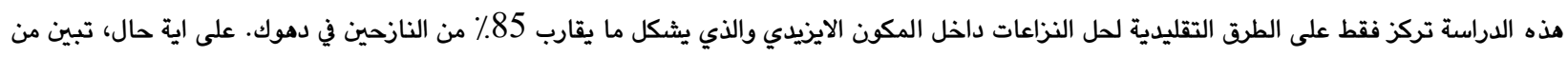

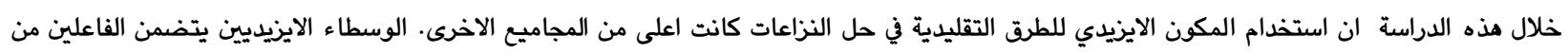
عامة المجتمع الايزيدي و الطبقة الوسطى، مما جعلهم من المؤثرين في مجال بناء السلام بسبب تفاعلهم المكثف مع اطراف النزاع و قابليتهم باستمرار في تطبيق الطرق التقليدية لحل النزاعات على الوضع او النزاع الحاصل.

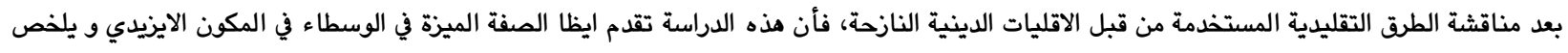

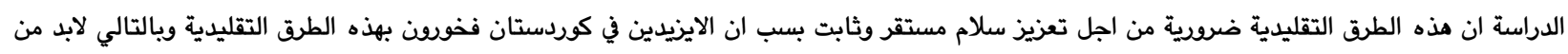
دعم عملية فهم هذه الوسائل و تقليص الاستياء حولها. الكلمات دالة: وسيط، الطرق التقليدية، النازحين، النزاع، حل النزاعات.

يوخته:

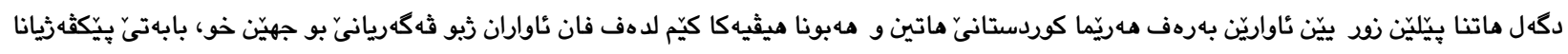

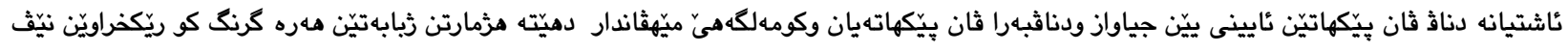

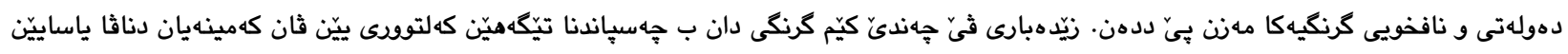

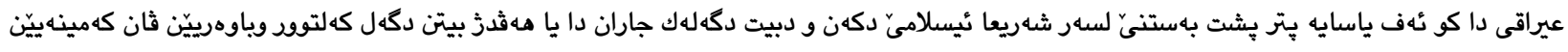

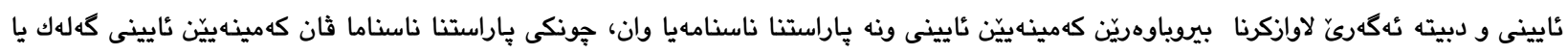

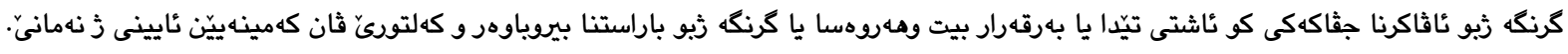

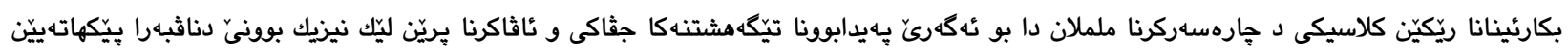

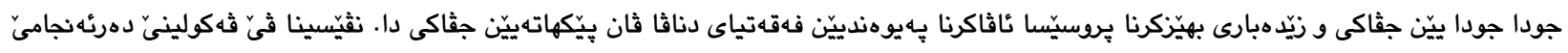

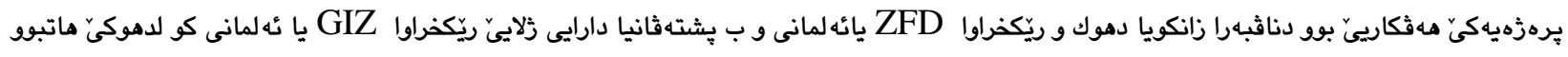

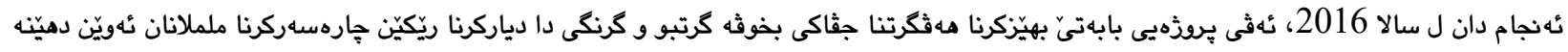

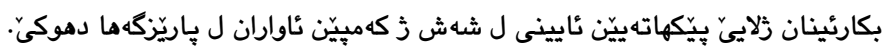

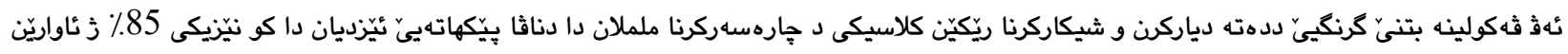

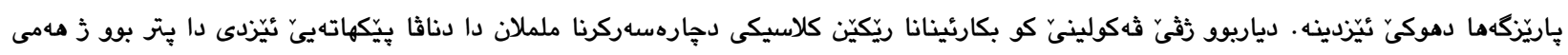

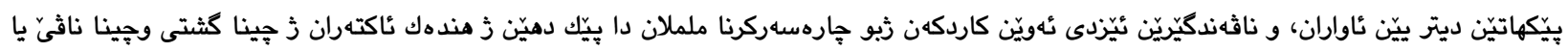

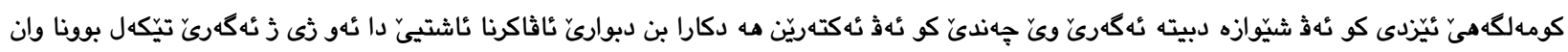

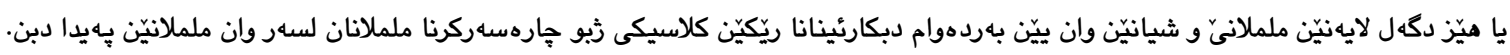

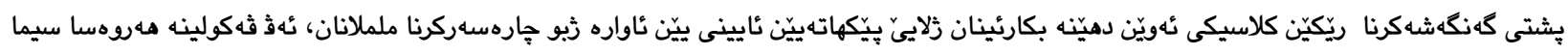

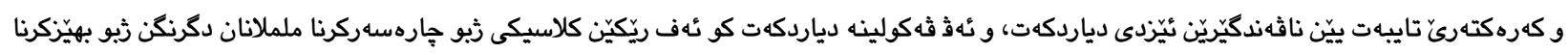

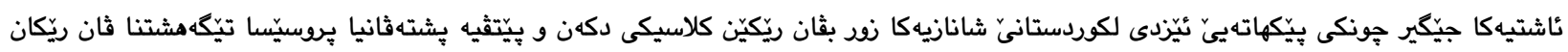

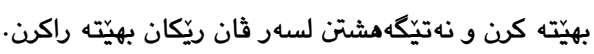

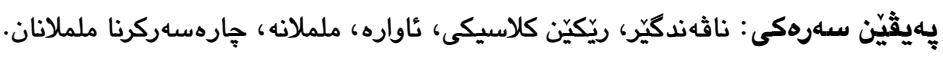

